\author{
JURNAL PENJAMINAN MUTU \\ LEMBAGA PENJAMINAN MUTU \\ UNIVERSITAS HINDU NEGERI \\ I GUSTI BAGUS SUGRIWA DENPASAR
}

Volume 7 Nomor 22021

ISSN : 2407-912X (Cetak)

ISSN : 2548-3110 (Online)

http://ejournal.ihdn.ac.id/index.php/JPM

\title{
MGA KWENTO NG GURO AT KWENTONG MAG-AARAL: STUDENT ASSESSMENT PROCESSES, CHALLENGES AND SOLUTIONS IN THE NEW NORMAL SETUP LEADING TO QUALITY ASSURANCE INPUTS
}

\author{
Oleh \\ Aljon Delmo Galang ${ }^{1}$, Rosie Lopez Conde ${ }^{2}$, I Ketut Sudarsana ${ }^{3}$ \\ ${ }^{1) 2}$ Philippine Normal University - Manila, ${ }^{3)}$ Universitas Hindu Negeri I Gusti Bagus Sugriwa \\ galang.ad@pnu.edu.ph ${ }^{1}, \underline{\text { conde.rl@pnu.edu.ph }{ }^{2}, \text { ulakan82@gmail.com }^{3}}$
}

diterima 30 April 2021, direvisi 15 Mei 2021, diterbitkan 31 Agustus 2021

\begin{abstract}
This qualitative research study used narrative approach to retell the narratives of twelve (12) high school teachers on the processes, challenges, and solutions of student assessment. The investigation identifies that teachers assess the students by utilizing modules and other activities as alternatives of face-toface instruction and assessment, using rubrics and providing feedbacks, utilizing online platforms, and involving parents. The participants also encountered challenges such as academic dishonesty, students' attitude towards learning tasks, and lack of ICT resources. These are solved by communicating with parents, feedbacking, and alternatives means of distributing learning tasks. The findings provide insights specifically for teachers who struggle in assessing student learning in the New Normal Setup and who aim to use distance learning even in the post-pandemic class setting; and contribute inputs to quality assurance in education, considering the pandemic-impacted educational landscape.
\end{abstract}

\section{Keywords : Quality Assurance, Student Assessment, Distance Learning}

\section{INTRODUCTION}

Education is seen as a tool of positive change in all facets of both local and international communities (Organization for Economic Co-operation and Development [OECD], 2015). This is the reason that stakeholders are always on guard to assure its quality, starting from lesson planning to its assessment. In other words, its facets must be checked all the time to make sure that students as the ultimate beneficiaries of the teachinglearning process, receive the best that they can learn. However, due to the pandemic, the educational landscape in the Philippines and abroad has been reshaped because of the limits it continuously creates. Literally and figuratively, the disease breaks the links that bind the learners to school. This leads to the 
perplexities not only in delivering instruction, but most especially in assessing learning. Student assessment (SA) is indeed indispensable in the edification experience, since it is a way to keep track of students' learning (Murnane, Sharkey, \& Boudett, 2005). However, even assessment is affected by the existence and persistence of CoViD19. Arduous it may seem, teachers being the front-liners of education still stand firmly to battle with this challenge in the New Normal classroom as it is one of the immense impacts of the instructional shift. Since there is an existing apprehension, the more that quality assurance is needed. Therefore, SA must also be subjected to quality assurance (QA) even in the face of the global permeating disease.

In any forms of service, QA is indispensable, and since educating a child is an epitome of such, QA and education cannot be taken as entities from separate parameters due to the fact that in education, there must be $\mathrm{QA}$, and in QA, there is education. In other words, the former emphasizes the importance of constantly checking the outcomes of education as it brings out useful insights that edify the practitioners on how to improve their service in the future and even in trying times (Joseph \& Joseph, 1997). This is true in student assessment. In the upsurge of the pandemic, assessing learning becomes a pressing subject of inquiry. In the Philippines, the country's Education Department provides Department Order No. 31, s. 2020 or also known as Interim Guidelines for Assessment and Grading in Light of the Basic Education Learning Continuity Plan to assess students appropriately, considering the health crisis of the public (Philippine Department of Education [DepEd], 2020). Since human physical contact is the primary cause of the pandemic's rapid permeation, it is avoided. Hence, the agency structures and implements learning modalities (LDMs) suitable for distance learning (DL). DL is a way of teaching and learning in far proximity from the physical school. Teachers deliver education to learners through different means such as online synchronous and/or asynchronous learning, printed and/or digital modular learning, television and/or radiobased instruction, and blended learning (Almario \& Austria, 2020). LDMs are intertwined with SA since assessment itself is delivered with instruction (Ancho, 2020). In other words, whatever instruction modality is used becomes the means of assessment. Nonetheless, online or offline, assessment becomes a challenge for teachers, leading to emerging issues. Moreover, due to the teacher-learner proximity, teachers' absence in real-time monitoring of students' tasks leading to assessment, and the lack of information and communication technologies (ICT) learning tools, questions on how students are assessed (processes), what hampers reliable assessment (challenges), and how teachers address such issues (solutions) remain unanswered.

Furthermore, in quality assurance in education, the school's provisions are systematically reviewed to keep and make its quality, equity, and efficiency better. It involves the school self-evaluation, external evaluation, teacher, school heads, and student assessment evaluation (European Commission, n.d.). To understand QA in education, there are researches that can be used to decode its nature. A study reveals that QA approaches in education are more on institutional rather than student-focused, and accountability-led rather than improvementled (Chung Sea Law, 2010). Another study focuses on the trend waves in quality assurance in education. It highlights the shift foci from internal quality assurance (first wave), satisfaction and accountability of internal and external stakeholders (second wave), to relevance to new education paradigm such as contextualized multiple intelligences (CMI), globalization, localization, and individualization (third wave) (Cheong Cheng, 2003). Thus, it can be realized that the previous study implies that the context shapes the nature of QA. However, a contradicting research shows that the nature of education is shaped based on the existing QA mechanisms (Tee $\mathrm{Ng}, 2008$ ). This is also true in a similar Danish study. The study implies that the country's trend in QA 
remolds the teachers and schools themselves (Andersen, Dahler-Larsen, \& Pedersen, 2009). On the other hand, the idea that QA must be based on the trends in education of the epoch is another related investigation, focusing on the QA in distance education. This research challenges the idea of using the same conventional QA mechanisms used for traditional education to distance education evaluation. It argues that the latter must use a different set of perspectives and mechanisms since there is a shift in trend (Stella \& Gnanam, 2004). This only implies that there must be a shift of mechanisms based on the situation that the school is in. Nevertheless, in this study at hand, the focus is not to perform quality assurance evaluation among the schools of the participants, but to provide inputs to reshape the mechanisms of quality assurance in student assessment in the New Normal.

In general, student assessment cannot be separated from the curriculum design and its implementation across instruction. It is about the instructional means and their outcomes. It allows both teachers and learners to track their progress through feedback and it also identifies whether the learners are able to meet the target learning results (Evans \& Bunescu, 2020; Russell \& Airasan, 2012; Shermis \& Di Vesta, 2011). Furthermore, there are studies related to student assessment in distance learning that can be used to further improve the delivery of instruction. In fact, there is a study extrapolating student assessment strategies. In the study, five (5) strategies of distance learning assessment are discussed, such as (a) establishing and communicating clear learning strategies, (b) establishing and communicating clear criteria for success, (c) building in opportunities for students to self-assess or ask questions, based on criteria, (d) giving brief, clear actionable feedback based on the criteria, and (e) giving students opportunities to revise assignments or re-do similar assignments (National Center on Educational Outcomes, 2020). Aside from this study on how assessment may be done properly in distance learning, there is also a study that talks about the preference of the students on how they may be assessed. In a Nigerian study on student assessment and distance learning in mathematics, it is revealed that students preferred traditional way of assessment such as through paper and pen since they can express their computations better (Reju \& Jita, 2020). Another study emphasized the importance of student assessment results to improve instruction as they are the springboards of progressive learning and instruction improvement (Murnane, Sharkey, \& Boudett, 2005). These studies imply the multiple facets of student assessment in distance learning.

Though there are varied studies that can be used as patterns to perform assessment in distance learning appropriately, what makes this study at hand different is its goal of retelling the narratives of public-school teachers who experience the assessment in distance learning for the first time due to today's general health crisis. In other words, these are teachers who are still adapting with the New Normal setup. Furthermore, this research does not focus on what is and/or should be assessed among learners, but on the 'processes' used by the teacher participants to assess students' learning, the 'challenges' they encountered in doing so, and the 'solutions' they formulated and utilized to address such.

This study aims to narrate the stories of student assessment means, challenges, and solutions made by language, science, math, and technical-vocational-livelihood high school teachers. Hence, this investigation targets to answer the following questions: (a) How did the teacher participants assess their learners in the New Normal? (b) What challenges in student assessment did these teachers encounter? (c) How did the participants address those challenges?

Furthermore, this research is executed (a) to provide insights specifically for teachers who struggle in assessing student learning in the New Normal Setup and who aim to use distance learning even in the post-pandemic class setting; and (b) to contribute inputs to quality assurance in education, considering 
the pandemic-impacted educational landscape.

\section{METHODOLOGY}

To capture the teacher participants' life special events related to the student assessment means, challenges, and solutions in the New Normal setup, contributing inputs to assessment itself and quality assurance in education, qualitative research method particularly narrative research is used in this empirical investigation. Qualitative research method's concern is on the quality of relational connections, individual and group behaviors, circumstances, and materials. In other words, the data analyzed and interpreted in this method is non-numerical (Fraenkel \& Wallen, 2009). This method fits the data nature of the study at hand. Furthermore, the teacher participants' stories are the data used in this investigation; thus, the suitable approach is narrative research. When the gathered data are entire stories or life episodes of selected participants, this approach is indeed applicable. (Fraenkel \& Wallen, 2009; Creswell, 2012).

Moreover, since the main concern of the study is student assessment in distance learning, twelve (12) high school teachers of language, science, mathematics, and technical-vocational-livelihood (TVL) who experience assessing student in distance learning for the first time, were chosen as participants. Language, science, and mathematics teachers were selected because the subjects they teach are the targets of Programme for International Student Assessment (PISA) (OECD, n.d.). Moreover, TVL teachers were chosen because the subject they teach is skill-based which is challenging to execute in distance learning. Participants 1 to 3 are language teachers, 4 to 6 are mathematics teachers, 7 to 9 are science teachers, and 10 to 12 are TVL teachers. Hence, purposive sampling is used in this study. It is a technique in sampling in which participants are chosen based on the categories needed in the study (Fraenkel \& Wallen, 2009; Creswell, 2012).
The teacher participants were asked to narrate their stories (special events) of student assessment means, challenges, and solutions (researcher-participant collaboration). Constant member checking was done before these narratives were re-storied in this study.

\section{Results and Discussion}

This section discusses the different processes of student assessment and the challenges encountered by the teacher participants. The solutions they used to address those are also elaborated in each theme.

\section{Process of Student Assessment 1: Modules and Other Activities as Alternatives of Face-to-Face Instruction and Assessment}

One of the responses of the Education Department to address the need for distance learning is the use of modules and other learning activities (DepEd, 2020). These are used as an alternative of on-site classroom interactions and in the absence of the teachers. A module contains parts such as checking of schemata, discussion of the topic, assessment of learning, and reinforcement activities (DepEd, 2021). In other words, as confirmed by Participant 12, modules are tools not of instruction, but also, of assessment. In fact, to Participant 2, student assessment begins with module distribution.

"In the process of delivering
instruction through the
content of the module itself,
another set of assessment
were provided. Through
activities students adaptation
and absorption of lessons are
being measured (Participant
12, Excerpt 1)."

"Student assessment starts with the distribution of the self-learning modules. It is a material designed to teach learners at the comfort of their home. It composed of activities that are arranged 
into progression (Participant

2, Excerpt 2)."

Modules are made to facilitate learning in the absence of teachers. Hence, it must be made in such a way that the students can answer it on their own especially the parts meant for assessment. Due to this reason, instruction must be easily understood and exercise must not only be simple, but measurable as confirmed by Participant 3 .

"These Self-Learning
Modules are designed to be
answered personally by the
students. The exercises and
directions are simple and
measurable (Participant 3,
Excerpt 3)."

There are other learning materials prepared to facilitate and assess student learning. Participant 1 said that learning activity sheets are made to meet the specific targets from the Most Essential Learning Competencies (MELCs). Modules are produced by the schools division offices, but as Participant 1 narrated, teachers modify them to fit into the academic proficiency and learning milieu of the students.

\section{"I also make Learning Activity Sheets which give me the freedom to target a specific objective from the MELCs. I also make some modification of activities from the modules because some activities there are too complicated for the students (Participant 1, Excerpt 4)."}

Furthermore, answering the modules may vary in speed, depending on the students capability. Hence, teachers give consideration to the students by giving them sufficient time to accomplish those. In fact, this is emphasized by Participant 7 .

"Giving considerations and ample time to the learners who were not able to submit modules or Learning Activity Sheet (LAS) on time (Participant 7, Excerpt 5)."

Furthermore, expected outputs for student assessment may also come in varied forms. As told by Participant 10, they may be in written works or performance tasks. TVL students who are required to develop skills cannot only be assessed through written works. Thus, demonstrations are recorded to be rated. However, not all students can cope up easily. Due to this reason, remedial activities are also given as confirmed by Participant 2.

"For TVL students whether
its online or modular
learning, I required them to
do an actual demonstration
of the skill they learned from
the lesson. They are required
to submit a videos of specific
skill they acquired out of the
lesson. Giving other task or
activities like essays,
collage, illustration can also
be a form of evaluation if the
students learned or lagging
behind (Participant 10,
Excerpt 6)."
"Whenever there are
students who fail to meet the
set standards, I give them
remedial activities to help
them catch up with the
lesson (Participant 2,
Excerpt 7)."

As implied in the discussion, it appears that distance learning in the schools is primarily modular. This entails that the assessment becomes output-based. Hence, the need for a tool to assess those follows. This is when rubrics and feedback come in.

Process of Student Assessment 2: Rubrics and Feedbacks as Tools of Student Assessment 
Rubrics and feedbacks are still essential in assessing student learning even in distance learning. Outputs that serve as evidences of learning serve are best assessed when the two are used since the former clarifies whether the output has met the criteria set and the latter presents the progress of the learners right away.

Rubrics are assessment tools that guide the teachers in rating the outputs of the students. It is composed of criteria with corresponding points based on the extent of performance and content standard compliance (Andrade and $\mathrm{Du}, 2005$ ). This helps teachers in assessing the works of the students objectively since it describes and defines output elements to consider. Furthermore, as confirmed by Participants 2 and 4, it assists the teacher in conducting remedial activities and guides the students to come up with the right output.

"I had this experience where $a$ student (Ivan) just answered the assessments in the modules by just copying the answers in the answer key. The learner did not even exert extra effort in constructing sentences on his own. I told him and the guardian that he needs to accomplish all the exercises as well as the additional activities that will test his understanding about the lesson. Weeks passed, the learner (with the help of the guardian) submitted a wellconstructed output. I assessed the output using a rubric (Participant 2, Excerpt 8)."

"The other remaining domains of learning needs to be assessed to ensure that learning was attained. To complete the assessment process we give them a performance task. This is a teacher-made task that will showcase the new skills acquired by the learners. It can in a form of developing an object that requires specific skills or an act that will manifest the needed skill. A rubric, another special tool is provided to help measure if the task is done successfully (Participant 4, Excerpt 9)."

Immediate feedback is also important in the process of assessment. It helps the students know their strengths and weaknesses in the task they did, and/or in the output they made. It also motivates the students since they see that their efforts are rewarded with good scores (Pat-El, Tillema, \& Koppen, 2012). Hence, this allows them to perform better as they involve themselves in the instructional experience as a whole. Participants 1 and 3 agree on this assertion.

"Once passed after the retrieval of modules, these will be checked and the score to be sent to them either thru group chats and personal messages. They have to be aware of their scores with a great motivation included in the messages. Doing so will remind them of an extra effort they have to exert in order to learn more (Participant 3, Excerpt 10)."

"Giving feedback is one of the ways that I use in assessing the learners. It is one of the important part of the assessment. I provide feedback to guide me in assessing the work of the student. It also serves as a motivation for them to achieve more in learning (Participant 1, Excerpt 11)." 
However, aside from these tools of assessment, another facet to talk about is the means through which these outputs are submitted from the students to the teachers to engage in the process of assessment even in the presence of the pandemic.

\section{Process of Student Assessment 3: Online Platforms as Means of Assessment}

It is true that technology plays a vital role in today's trying situation especially in assessing students in distance learning (Kirkwood \& Price, 2008). Online platforms such as Google Forms and Facebook Messenger become a way not only to communicate, but also to transfer evidences of learning. They have become platforms for the students to submit their works and for the teachers to gather those and assess them eventually. In fact, as shared by Participant 1 , students become active when these platforms are used.

"During this new normal, I
also maximize my resources
like gadgets and internet
connection. I use Google
Form Quiz for some of my
activities. One of the reasons
why I decided to use this
platform is because I notice
that some students actively
participate in the activity.
Maybe they are curious on
how to use the platform that
is why they response
immediately. Somehowitgets
their interest. For those
without internet connection, I
simply send the activity in
Messenger and wait patiently
for their answers
(Participant 1, Excerpt 12)."

It is possible for the students to view their scores upon taking their quiz through Google Form. This favors immediate feedbacks that can help identify whether the students are able to meet the content standards of the subject. This is told by Participant 6 .
"For synchronous learners, I opted to use google forms as one of the means of assessment. With the use of google forms, I was able to provide an assessment with a variety of test questions. Multiple choices, short paragraph essays, checklists, test of veracity (True or False) were some of the type of questions I utilized. It is easy to use since the learner can view his score already and can self-reflect what he learned from the topic. With the use of google forms, I can immediately recognize who among my learners have met the objectives of my lesson (Participant 6, Excerpt 13)."

In the unavailability of strong internet connection, Facebook Messenger (FM) becomes the best alternative to submit and take quizzes. Since sending messages in FM is possible even one simply uses free data, this serves as the most practical way to send outputs to the teachers. This is known to Participant 11. Hence, this platform is used as an option for students.
"One way of assessing students is through google form. When I used google form, some of my students failed to take it because of internet problems. There is a time that a parent approaches me about using $i t$, she said that she thought we are modular, so why is that we are using google form? She said that they don't have internet connection at home, so I answered it is not mandatory. The student can still answer it using free data via messenger or I can 
send it to the student. Due to

the recent quarantine procedure implemented in our area we can just do online teaching \& learning. I provide them a learning activity sheet per week. Students accomplish the assessment then afterwards send their answers via available platform (Participant 11, Excerpt 14)."

With these available platforms, communicating and sending of outputs and feedbacks become possible. Nevertheless, the real battle in distance learning and assessment is at home. Students find it difficult to do their tasks alone without the help of their parents and guardians.

\section{Process of Student Assessment 4: Parental Involvement in Student Assessment}

In the absence of teachers, parents become the immediate figure of learning facilitation. They have the supervisor of students' learning. In other words, parents play a vital role in students' learning (Goodall \& Montgomery, 2013). However, learning will only take place when the parents allow it to happen. When they facilitate the learning of their children with vigilance and honesty, students will definitely learn. This is claimed by Participant 4 .

"Answering tasks at home requires honesty as a foundation because every SLM has a key to correction at the last page. In order to materialize things, one must have a good supervision of the guardian or a reliable heart (Participant 4, Excerpt 15)."

"In modular DL, students were given learning modules to study and answer by themselves or with the help of their parents/guardians

(Participant 9, Excerpt 16)."

Furthermore, when parents are available to communicate with, feedbacking becomes easy. Students learning is indeed a teamwork between parents and teachers. As the students submit their works, the teachers must give feedback to the parents right away so that they can help their children in achieving the expected outputs.

"Assessment comes in many forms but with a great objective of having basis of what to give or do next to our clienteles which are our learners. Parents are of big help. Since I am handling Grade 10 and a native of the barangay, I could personally inform the parents of the so far performance of their children. Be it based from the result from the summative or the performance test. At the end of the conversation, they seemed to be thankful. As I am always telling them, the teaching learning process is indeed a tough job nowadays but working hand in hand, learning is possible (Participant 3, Excerpt 17)."

\section{Student Assessment Challenge and} Solutions 1: Academic Dishonesty with Parents, through Answer Keys, and Online Academic dishonesty is a challenge that education battles with long before its advent (Davis et al., 1992; Edgren \& Walters, 2006). This happens even in the pre-CoViD-19 classroom and this intensifies when distance learning becomes the mode of instruction delivery. It comes in different forms, such as with parents, answer keys, and online. In this setup, teachers find it frustrating that parents involve themselves in such. Some parents do the tasks of their children at home, instead of simply facilitating them. Hence, this leads to 
invalid assessment of learning. There are experienced by Participants 1, 3, and 4 .

"It is hard to assess the works of students because there are times where I have doubts whether the student is the one who really answers the activity or someone else. Sometimes when I check the paper, it's very obvious that the one who answered is their parents because of the penmanship. It is really saddening that parents tolerate their children with this (Participant 1, Excerpt 18)."

"Instead of students answering/ performing the activities, instead of parents helping, they monopolize the answer (Participant 3, Excerpt 19)."

"In modular learning the learners are left to handle their own materials. Some of them may study it truly and some will not. In this way the assessment process is questionable. If the learners has no guardian to guarantee that they are doing the activities and test with all honesty then the result of the assessment is being compromised. The reliability of the results are on the hands of whether they answered it on their own or not (Participant 4, Excerpt 20)."

However, the teacher participants share their ways to address such problems. Participant 1 said that she compares the previous works to check whether the students asked other individuals such as parents and guardians to accomplish the given tasks. Participant 2 communicates with the students and parents about the emerging doubts of honesty in answering the learning materials. Participant 3 provides another set of tests to confirm whether the students really acquire what are expected of them. Through these tests, doubts can be lessened.

"When I feel like doubting, I try to track his or her previous activities and compare them. Then I keep on reminding them to be honest in answering the modules and activities. I try to instill the importance of values in their studies (Participant 1, Excerpt 21)."

"[I] call the attention of the student, have him realized the importance of learning by himself. [I] talk to the parent as well (Participant 3, Excerpt 22).'

"To address the issues on key to corrections in the SLMs, we provide summative test. It is sent to the learners in the form of a printed material or using Google forms. In that way, we can avoid the thought of them just copying their answers on the key to correction. It helps to lessen the doubts towards their actions. Yet this material will address the need to assess whether they acquired understanding or not (Participant 4, Excerpt 23)."

Another problem is that answer keys are provided in the modules given by the Schools Division Offices. This leads to doubts in the validity of the assessment. In fact, Participants 2 and 10 consider the assessment tool useless since it is easy for the students to see the answers. In fact, Participant 6 received responses that are apparently copied. The response is "Answers may vary". If this is indicated in the answer key, students have to respond in their own way. Unfortunately, that kind of copying happened.

"I also find it challenging to assess students. Students just copy the available answers 
found in the answer key section of the module. Even though I reiterated in the class that I give grades to the activities that answers will come from them, still they just don't pay attention (Participant 2, Excerpt 24)."

"In modular learning, the pre-assessment or summative assessment in the modules can't be used as a measuring tool because the answer key is a part of the module. I, the teacher, was always in doubt whether they answered truthfully or just copied the answers, especially when a learner perfected his/her score in every activity in the module (Participant 10, Excerpt 25)."

"Another problem I assessment in the new normal was learners copying answers from the answer key in the module. Since the DepEd provided answer key at the back of every module, some learners only copied the correct answers and did not even try to answer the assessment or activities by themselves. These learners can be easily detected because they also copy "Answers may vary" in the answer key. This case was common mostly on modular learners who were provided with printed modules (Participant 6, Excerpt 26)."

The participants find ways to solve this issue. Participant 2 simply gives extra points to those who do their works religiously and excellently as a form of motivation. Participant 10 even asked the help of an educational program specialist (EPS). The EPS emphasized the importance of providing additional written works and rubrics in assessing those. Participant 6 , being a math teacher, asked the students to provide solutions to exhibit how well they understand the target lessons.

"I just give consideration in checking their work. But I make sure that those who strive hard to come up with an output will have a grade that they deserve (Participant 2, Excerpt 27)."

"To be able to come up of another way to determine student's learning, I asked the help of our EPS on how to go around D.O. 31 s.2020. His advised was to make it as written work, in a form of short test or an essay. Short test should consist a maximum of 30 items or less, for the essay using a rubric for checking is essential. A minimum of 4 written works per quarter has been required (Participant 10, Excerpt 28)."

"In order to avoid students copying answers solely on modules' answer key, I instructed my learners to show their solutions in every item. For online learners, I asked them to take a picture of their computation and send it in the class' google drive folder. On the other hand, for my modular learners, they were required to submit their computations along with their answer sheets. Most students submitted their computation sheets but some students, still would not comply with the 
needed requirement (Part 6, Excerpt 29)."

Another problem is online cheating. When examinations are given online, the students simply browse the Internet to look for answers or they are provided with answers from those academically inclined students who have taken the tests first. This is confirmed by Participants 4 and 6 .

"Modular distance learning as it defines itself is a form of learning done at the comfort of your home. In this arrangement complete monitoring of the learners actions towards learning is compromise. Whatever test be given, the teacher is not there to see for themselves whether they are answering it on their own or not. Some may send answers via messenger or browse everything via Google. Some learners do not care to answer at all so assessing them is quite hard (Participant 4, Excerpt 30)."

"One of the challenges I encountered in assessing the learners in the distance learning is online cheating. In some cases, I have learned that students tend to send correct answers to their classmates or friends. One performing student would answer the quiz beforehand and he would help his friends get a higher or passing score. This is evident with students who were completing online quizzes. Since quizzes and tests were rendered online in the new normal, this was a common scenario. This was not only evident in my subject (Participant 6, Excerpt 31)."
Participant 4 argues that there is the only way to solve such and that is to have face-toface learning, which is impossible due to the existing heath crisis. The parents' assistance and guidance are seen as a solution to address such problem. Participant 6 shared that she uses feedbacks through weekly home learning plan. Eventually, parents see the comments and the students are expected to re-submit their works.

The only address I can see with this problem is a face-toface learning, which is impossible at this time of pandemic. Our health is the most important aspect nowadays, what is learning if one is dead. The only way we can do is to ask the support of the parents or guardians to assist their children in out absence. That they should impose rules at home so the learners will not be misled to cheating. To talk via phone calls, chats and even ask pictures of them doing the task. Giving assistance at all times, to the learners or to the guardians. Praying at all times that their love for truth will prevail (Participant 4, Excerpt 32).

With the problem stated above, in return, I put written feedback to those answer sheets instructing learners to follow instructions indicated in their weekly home learning plan. Through this, when parents retrieve the learner's checked answer sheet (AS), they can view what were still needed to accomplish. There were cases that learners would re-submit correctly answered tasks but there were some who would not re- 
submit AS. I would recognize learners who re-submit AS by posting their names in their class group chat/page (Participant 5, Excerpt 33).

\section{Student Assessment Challenge and}

Solutions 2: Students' Attitude towards

\section{Learning Tasks}

Students' attitude towards learning tasks is indeed an important element of learning since it drives them to the targets of instruction (Akhtar, 2007). When their attitude towards learning is negative, their performance will be hampered. This is one of the problems that Participant 11 encountered. Students do not focus even on their major assessment activities, leading to poor performance. Participant 6's students are already satisfied in submitting incomplete and/or wrong requirements and they do not follow the learning plan given. The same as the previous, Participant 3's students tend to neglect activities that take some time to accomplish. Participant 9 shared that her students are not motivated to accomplish their learning activities and not even performing well in the assessment given in class.

"Our school is implementing modular learning modality. Since that we are not meeting face to face their assessment were given in the next modules distribution. One of the problem we encounter is that some of the students just takes it for granted. They are not paying much attention on the summative test. Some of them are getting low score, some did not even write their names on the test paper. There are some cases that test paper were misplaced or mixed with other subject which is a common incident (Participant 11, Excerpt 34)."



To move the students to change their attitudes towards their learning tasks, Participant 11 gives remedial activities for low performing students. In case of lost activities, students are given time to look for those. They may send those through online 
platforms. Along with this consideration, the students are reminded that they need to take care of their submissions.

"In the cases that they have low scores, the students were given remedial test. Those students who fail to write their names will be identified after recording the scores because students with no scores will be announced in the group chat. In the case of the misplaced test papers, we will give time to find it, if not found I will send the screen shots of the test to be answered again by the students. The students will send back the picture of his/her answer. Then I will remind them to avoid such incident they must make sure to write their names and ask their guardian to place their paper on the designated subjects (Participant 11, Excerpt 38)."

Participant 6 reminds the students to follow the learning plan religiously to accomplish the tasks given correctly. In cases of wrong and/or incomplete submissions, proper communication with both the parents and students is done. This is also done by Participant 3. Participant 9 added the importance of feedbacking to reflect on how to address the needs and struggles of the students in this time of pandemic.

"With the problem stated above, in return, I put written feedback to those answer sheets instructing learners to follow instructions indicated in their WHLP. Through this, when parents retrieve the learner's checked AS, they can view what were still needed to accomplish. There were cases that learners would re-submit correctly answered tasks but there were some who would not resubmit AS. I would recognize learners who re-submit AS by posting their names in their class group chat/page (Participant 6, Excerpt 39)."

"Positively, I have to deal with the learner (thru text or pm)and with the parent/guardian as well during the distribution and retrieval of modules to remind them of the importance of not skipping any activity designed for them. Grades will be based from their scores (Participant 3, Excerpt 40)."

"Without modules for the teacher to examine or gauge student learning, there's pretty much nothing to measure. This could probably be addressed by getting feedback from the students. Feedback could enlighten us as to what the underlying reasons were for the behavior exhibited by the student towards modular learning in general. One way to get feedback would be to provide them a space or some means to express their thoughts and feelings to address the issue (Participant 9, Excerpt 41)."

Student Assessment Challenge and Solutions 3: Lack of Information, and Communication Technologies (ICT) Resources

One of the requirements of distance learning and assessment is ICT resources which are lacking among the students. This affects the students' learning and assessment 
(Van Brakel \& Chisenga, 2003). Since they are not updated of the announcement and reminders posted online, they are left out. This is what Participant 1 shared.

Another one is the lack of
resources for most of the
students. If everyone is
supported with gadgets and
internet connection, I think it
will easier to adjust in this
time of pandemic. Lack of
resources for most of them
also affects their motivation
to study. Since they do not
have the means, Ican'toblige
them to frequently check our
group chat for
announcements and
reminders (Participant 1 ,
Excerpt 42).

Participant 5 also added that students without ICT gadgets cannot raise their concerns to the teachers right away leading to dilemma in learning. In worst cases, this may lead to students' low performance in class. Participant 11 also narrated that since tests are given online, those who do not have internet connection suffer and are sometimes on the verge of failing. The participant added that it also limits the communication among teachers, students, and parents.

\section{"Another challenges that I encountered is when the learners is having difficulties in reaching out. A learner who doesn't have smart phones or even an ordinary cellphone. The learners having difficulties on asking questions about the topic that they don't understand. So the tendency is they just answer it even they knew that they are wrong. (Participant 5, Excerpt 43)."}

"Assessing the students and delivering instruction in this new normal is not easy for most of the teachers. Most of the students outputs, performances, activities and test are sent or given through text or messenger. Wherein, the results of all these, might not be directly coming from the students themselves. There are so many ways where students can find most of the answers easily, that is through Internet. Another thing, is that it will also be difficult to assess students performances because there is no personal contact /communication happening , unlike before in a real class situation or set up. Contacting or communicating with students is another problem commonly happening. Not all learners or students have cellphones or Internet connection at home due to this, problem in giving instructions as well delivering information arise (Participant 11, Excerpt 43)."

To beat the lack of ICT resources, Participant 1 provides printed learning activities and distributes those to them. The students are also motivated to accomplish those even in the absence of such resources. Participant 5 shared that considerations are always given to the students. The correct answers are written on the sheets to let them know how to perform such mathematical operations properly. This is a form of feedback. Participant 11 taps the help of those students with strong internet connection to help their classmates. Those students can communicate with teachers all the time are asked to inform their classmates about the learning tasks that must be accomplished. 
I am preparing LAS in prints and digital so for some will use the Google Form for those with internet connection and some will simple send me their answers on Messenger. I keep on motivating them by giving feedback and additional points whenever they accomplished a certain activity (Participant 1, Excerpt 44).

As a teacher we are very kind to our students. We always give consideration for every small or big effort that our students extend. That why when they try to solve the activities we give consideration for that but since it is new normal when I was checking the activities I see to it to write the correct answer for them to be guided and to understand the process on how I arrived to the correct answer (Participant 5, Excerpt).

Communicating with students who can't join Google meet can help or solve the problem of passing information, lesson and instructions to the students. Also we could ask for help from some of the students who have good internet connection so that they can rely information or instruction in accomplishing certain activities to their classmates in need if they are living in the same place. Also by having online instructions once in a while, helps us to see the actual response of Learners helps in assessing their performances. Asking help from former advisers of the learners is also one way of keeping in touch with the students (Participant 11, Excerpt 45).

\section{CONCLUSIONS}

The themes that have emerged from the narratives of the teachers lead to the following conclusions. Teachers assess the students by utilizing modules and other activities as alternatives of face-to-face instruction and assessment, using rubrics and providing feedbacks, utilizing online platforms, and involving parents. The participants also encountered challenges such as academic dishonesty, students' attitude towards learning tasks, and lack of ICT resources. These are solved by communicating with parents, feedbacking, and alternatives means of distributing learning tasks.

Impacts on Quality Assurance and Student Assessment. The findings of this study may be used as inputs to come up with quality assurance guidelines to improve distance learning and student assessment in this time of pandemic. Furthermore, the solutions presented to specific challenges may be of great help to those teachers who are in dilemma in assessing students in the current education setup.

\section{REFERENCES}

Ancho, I. (2020). Teaching Korean as a foreign language: Inputs to new normal pedagogy. Creative Practices in Language Learning and Teaching, $8(2)$, 27-38. Retrieved from https://cplt.uitm.edu.my/v1/images/v 8n2/Article3.pdf

Akhtar, M. (2007). A comparative study of student attitude, learning and teaching practices in Pakistan and Britain. Educational Studies, 33(3), 267-283. doi:10.1080/03055690701423069

Almario, A.R., \& Austria, R. (2020). Helping K-12 transition to post-COVID 19 times. $\quad$ Retrieved from https://authdocs.deped.gov.ph/wpcont ent/uploads/2020/06/BE-LCP-Annex- 
E-Ani-AlmarioHelping-K-12-

Schools-Transition-to-PostCOVID.pdf

Andersen, V. N., Dahler-Larsen, P., \& Pedersen, C. S. (2009). Quality assurance and evaluation in Denmark. Journal of Education Policy, 24(2), 135-147. doi:10.1080/02680930902733071

Andrade, H. \& Du, Y. (2005). Student perspectives on rubric-referenced assessment. Practical Assessment, Research, and Evaluation 10 (3). https://doi.org/10.7275/g367-ye94

Cheong Cheng, Y. (2003). Quality assurance in education: internal, interface, and future. Quality Assurance in Education, 11(4), 202-213. doi:10.1108/09684880310501386

Chung Sea Law, D. (2010). Quality assurance in post-secondary education. Quality Assurance in Education, 18(1), 64-77. doi:10.1108/09684881011016007

Creswell, J. (2012). Educational research: Planning, conducting, and evaluating quantitative and qualitative research. Boston, USA: Pearson Education, Inc.

Davis, S. F., Grover, C. A., Becker, A. H., \& McGregor, L. N. (1992). Academic Dishonesty: Prevalence, Determinants, Techniques, and Punishments. Teaching of Psychology, 19(1), 16-20. doi:10.1207/s15328023top1901_3

Edgren, S., \& Walters, S. (2006). Distance Learning Exchange: Academic Dishonesty in the 21stCentury. The Journal of Continuing Higher Education, 54(2), 5659. doi:10.1080/07377366.2006.1040 0101

European Commission. (n.d.). Why is quality assurance in school education important? Accessed 22 April 2021. Retrieved

from https://ec.europa.eu/education/policie s/school/quality-assurance en

Evans, C., \& Bunescu, L. (2020). Student assessment: Thematic peer group report. European University
Association. Retrieved from https://eua.eu/downloads/publications leua\%20report\%20student\%20assess ment_web.pdf

Fraenkel, J., \& Wallen, N. (2009). How to design and evaluate research in education. New York, USA: McGraw-Hill Companies, Inc.

Goodall, J., \& Montgomery, C. (2013). Parental involvement to parental engagement: a continuum. Educational Review, 66(4), 399-410. doi:10.1080/00131911.2013.781576

Joseph, M., \& Joseph, B. (1997). Service quality in education: a student perspective. Quality Assurance in Education, 5(1), 15-21. doi:10.1108/09684889710156549

Kirkwood, A., \& Price, L. (2008). Assessment and student learning: a fundamental relationship and the role of information and communication technologies. Open Learning: The Journal of Open, Distance and eLearning, 23(1), 5-16. doi:10.1080/02680510701815160

Murnane, R. J., Sharkey, N. S., \& Boudett, K. P. (2005). Using Student-Assessment Results to Improve Instruction: Lessons From a Workshop. Journal of Education for Students Placed at Risk (JESPAR), 10(3), 269-280. doi:10.1207/s15327671espr1003_3

National Center on Educational Outcomes. (2020). Five formative assessment strategies to improve distance learning outcomes for students with disabilities. Retrieved from https://nceo.umn.edu/docs/OnlinePub s/NCEOBrief20.pdf

Organization for Economic Co-operation and Development. (2015). The role of education and skills in today's world. Retrieved from https://www.oecdilibrary.org/docserver/978926422615 9-4-

en.pdf?expires $=1619110343 \& i d=i d \&$ accname $=$ guest\&checksum $=$ BDA45F B25CC55651174E1478C9F6CE63 
OECD. (n.d.). What are the goals of the PISA for Schools project? Accessed April 22, 2020. Retrieved from https://www.oecd.org/pisa/aboutpisa/ pisa-based-test-for-schoolsfaq.htm\#: :text=The\%20PISA\%20fo r\%20Schools\%20project\%20aims\%2 0to\%3A, and \%20the\%20world\%20of $\% 20$ work.

Pat-El, R., Tillema, H., \& van Koppen, S. W. M. (2012). Effects of formative feedback on intrinsic motivation: Examining ethnic differences. Learning and Individual Differences, 22(4), 449-454. doi:10.1016/j.lindif.2012.04.001

Philippine Department of Education. (2021). Guidelines on the evaluation of selflearning modules for quarter 3 and 4 for school year 2020-2021. (DepEd Order No. 001). Department of Education Official Website. Retrieved from https://www.deped.gov.ph/wpcontent/uploads/2021/01/DO_s2021 001.pdf

Philippine Department of Education. (2020). Interim guidelines for assessment and grading in the light of the basic education learning continuity plan. (DepEd Order No. 31). Department of Education Official Website. Retrieved from https://www.deped.gov.ph/wpcontent/uploads/2020/10/DO_s2020 031.pdf

Philippine Government. Department of Education. (2020). DepEd prepares self-learning modules for education's new normal. Department of Education Official Website. Retrieved from https://www.deped.gov.ph/2020/07/0 2/deped-prepares-self-learningmodules-for-educations-new-normal/

Reju, C. O., \& Jita, L. C. (2020). A comparative investigation of assessment practices in distance and online learning undergraduate mathematics in Nigeria. Journal of Educational Research and Practice, 10, 90-103. https://doi.org/10.5590/JERAP.2020. 10.1 .06

Russell, M. \& Airasan, P. (2012). Classroom assessment: Concepts and applications. New York, USA: McGraw-Hill Companies.

Schartel, S. A. (2012). Giving feedback - An integral part of education. Best Practice \& Research Clinical Anaesthesiology, 26(1), 7787. doi:10.1016/j.bpa.2012.02.003

Shermis, M. \& Di Vests, F. (2011). Classroom assessment in action. Plymouth, UK: Rowman \& Littlefield Publishers, Inc.

Stella, A., \& Gnanam, A. (2004). Quality assurance in distance education: The challenges to be addressed. Higher Education, 47(2), 143-160. doi:10.1023/b:high.0000016420.1725 $1.5 \mathrm{c}$

Tee Ng, P. (2008). The phases and paradoxes of educational quality assurance. Quality Assurance in Education, $16(2)$,

112-125. doi:10.1108/09684880810868402

Van Brakel, P. A., \& Chisenga, J. (2003). Impact of ICT-based distance learning: the African story. The Electronic Library, 21(5), 476-486. doi:10.1108/02640470310499867 